Article

\title{
Biophysical Characterization of Epigallocatechin-3-Gallate Effect on the Cardiac Sodium Channel $\mathrm{Na}_{\mathrm{v}} 1.5$
}

\author{
Mohamed-Yassine Amarouch ${ }^{1, *}$, Han Kurt ${ }^{2}$, Lucie Delemotte ${ }^{2}$ and Hugues Abriel ${ }^{3, * \mathbb{D}}$ \\ 1 R.N.E Laboratory, Multidisciplinary Faculty of Taza, University Sidi Mohamed Ben Abdellah of Fez, \\ Fez 30000, Morocco \\ 2 Science for Life Laboratory, Department of Applied Physics, KTH Royal Institute of Technology, \\ SE-100 44 Solna, Sweden; han.kurt@outlook.com (H.K.); lucie.delemotte@scilifelab.se (L.D.) \\ 3 Institute of Biochemistry and Molecular Medicine (IBMM), University of Bern, 3012 Bern, Switzerland \\ * Correspondence: mohamed.amarouch@usmba.ac.ma (M.-Y.A.); hugues.abriel@ibmm.unibe.ch (H.A.)
}

Academic Editors: Saverio Bettuzzi and Jean-Marc Sabatier

Received: 26 December 2019; Accepted: 15 February 2020; Published: 18 February 2020

check for updates

\begin{abstract}
Epigallocatechin-3-Gallate (EGCG) has been extensively studied for its protective effect against cardiovascular disorders. This effect has been attributed to its action on multiple molecular pathways and transmembrane proteins, including the cardiac $\mathrm{Na}_{\mathrm{v}} 1.5$ channels, which are inhibited in a dose-dependent manner. However, the molecular mechanism underlying this effect remains to be unveiled. To this aim, we have characterized the EGCG effect on $\mathrm{Na}_{\mathrm{v}} 1.5$ using electrophysiology and molecular dynamics (MD) simulations. EGCG superfusion induced a dose-dependent inhibition of $\mathrm{Na}_{\mathrm{V}} 1.5$ expressed in tsA201 cells, negatively shifted the steady-state inactivation curve, slowed the inactivation kinetics, and delayed the recovery from fast inactivation. However, EGCG had no effect on the voltage-dependence of activation and showed little use-dependent block on $\mathrm{Na}_{\mathrm{v}} 1.5$. Finally, MD simulations suggested that EGCG does not preferentially stay in the center of the bilayer, but that it spontaneously relocates to the membrane headgroup region. Moreover, no sign of spontaneous crossing from one leaflet to the other was observed, indicating a relatively large free energy barrier associated with EGCG transport across the membrane. These results indicate that EGCG may exert its biophysical effect via access to its binding site through the cell membrane or via a bilayer-mediated mechanism.
\end{abstract}

Keywords: EGCG; $\mathrm{Na}_{\mathrm{v}} 1.5$; cellular electrophysiology; molecular dynamics; ion channels

\section{Introduction}

Ion channels are pore-forming transmembrane proteins involved with the transport of ions through cell membranes. Their activity is essential for the excitation-contraction coupling in cardiac cells. In this sense, the voltage-gated sodium channels generate the rapid action potential upstroke of cardiomyocytes and thereby play a crucial role in heart excitability and conduction.

Within the nine isoforms of voltage-gated sodium channels, $\mathrm{Na}_{\mathrm{v}} 1.5$ displays a preponderant expression in cardiac cells [1]. This isoform is composed of intracellular $\mathrm{N}$ and $\mathrm{C}$ terminal tails and four homologous domains (DI-DIV), each consists of six transmembrane segments (S1-S6). These domains fold together with their S5-S6 segments to build a highly selective $\mathrm{Na}^{+}$pore $[2,3]$.

$\mathrm{Na}_{\mathrm{v}} 1.5$ dysfunction is linked with an increasingly wide range of inherited cardiac arrhythmias [4,5]. Gain-of-function mutations of this channel are associated with many disorders such as the congenital long QT syndrome, multifocal ectopic Purkinje-related premature contractions (MEPPC), and exercise-induced polymorphic ventricular tachycardia [6-11]. Whereas the loss-of-function 
mutations are linked with Brugada syndrome, sick sinus syndrome, and cardiac conduction disease $[4,5,12]$. In the same line, mutations in genes encoding proteins that regulate, directly or indirectly, $\mathrm{Na}_{\mathrm{v}} 1.5$ function are associated with many cardiac arrhythmias [13]. This is true for many $\mathrm{Na}_{\mathrm{v}} 1.5$-interacting proteins such as $\mathrm{Na}_{\mathrm{v}}-\beta$ subunits, Plakophillin-2, and more recently for the nuclear proteins Lamin $\mathrm{A} / \mathrm{C}$ [14-17]. As such, $\mathrm{Na}_{\mathrm{v}} 1.5$ channels become highly targeted by several drug classes, including anti-arrhythmic drugs [18], despite their associated side effects [19].

In this context, bioactive molecules extracted from medicinal plants are pledged to offer added values in preventing arrhythmic episodes. Epigallocatechin-3-Gallate (EGCG), the predominant polyphenol of green tea, was shown to be a promising natural alternative in the setting of cardiac arrhythmia $[20,21]$.

Green tea extracts and EGCG have been extensively studied for their protective effects against cardiovascular disorders. Many authors have shown that green tea consumption is associated with a lower risk of heart disease and reduced cardiovascular mortality [22,23]. Moreover, several experimental studies revealed that EGCG reduces chronic ventricular remodeling after myocardial ischemia in rats [24], improves left ventricular dysfunction, suppresses myocardial inflammation in rat autoimmune myocarditis [25], modulates arrhythmogenic activity, and calcium homeostasis of rabbit left atrium [21], and inhibits angiotensin II-induced cardiomyocyte hypertrophy [26].

The cardiac activity of EGCG has been attributed to its effect on multiple intracellular molecular pathways and transmembrane proteins [20-22,26-28], including $\mathrm{Na}_{\mathrm{v}} 1.5$. This compound has shown a dose-dependent inhibitory effect on the cardiac sodium current $\mathrm{I}_{\mathrm{Na}}[21,29,30]$. However, the molecular and biophysical mechanism underlying this effect remains to be unveiled. To this aim, we have worked out to characterize the mechanisms underlying the EGCG effect on the cardiac sodium channel $\mathrm{Na}_{\mathrm{v}} 1.5$.

\section{Results}

\subsection{Inhibitory Effect of EGCG on Human $N a_{v} 1.5$ Channels}

The pharmacological effects of EGCG (Figure 1a) on the cardiac sodium channel isoform were investigated using tsA201 cells transiently transfected with the human $\mathrm{Na}_{\mathrm{v}} 1.5$ channel in the presence of its regulatory subunit $\mathrm{Na}_{\mathrm{v}}-\beta 1$. The latter is known for its effect on increasing the functional expression of $\mathrm{Na}_{\mathrm{v}} 1.5$ channels in many heterologous systems [14]. $\mathrm{I}_{\mathrm{Na}}$ currents were generated by $15 \mathrm{~ms}$ step depolarization to $-20 \mathrm{mV}$ from a holding potential of -100 or $-80 \mathrm{mV}$ at a frequency of $0.33 \mathrm{~Hz}$. As previously reported by Kang et al. [30], EGCG superfusion induced a dose-dependent inhibition of the $\mathrm{Na}_{\mathrm{v}} 1.5$ channel. The $\mathrm{IC}_{50}$ for the EGCG inhibition was $31.2 \pm 3.6 \mu \mathrm{M}$ when measured from the $-100 \mathrm{mV}$ holding potential (Figure $1 \mathrm{~b}-\mathrm{d}$ ) and $2.1 \pm 1 \mu \mathrm{M}$ when measured at $-80 \mathrm{mV}$ (Figure 1e,f). On the other hand, EGCG dose-dependent effect on the fast inactivation kinetics was investigated. This resulted in slowing the inactivation kinetics as long as the EGCG concentrations increased, mainly at 50 and $100 \mu \mathrm{M}$ (Supplementary Figure S1). 
<smiles>O=C(O[C@H]1Cc2c(O)cc(O)cc2O[C@H]1c1cc(O)c(O)c(O)c1)c1cc(O)c(O)c(O)c1</smiles>

\section{Epigallocatechin-3-Gallate}

(a)

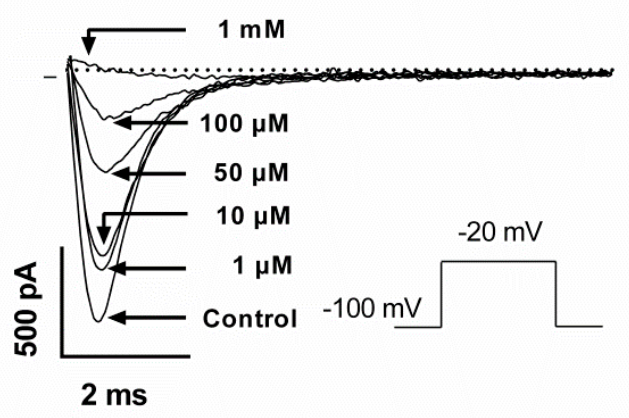

(c)

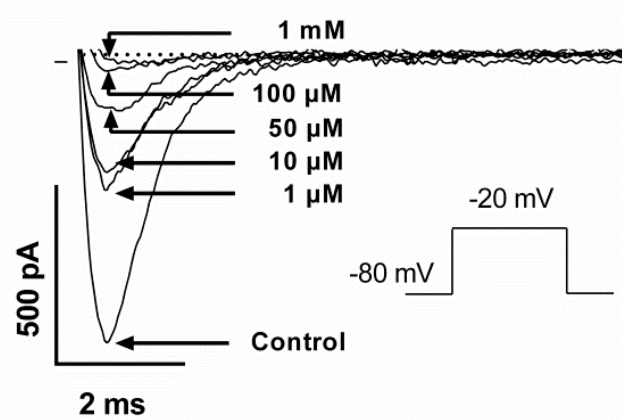

(e)

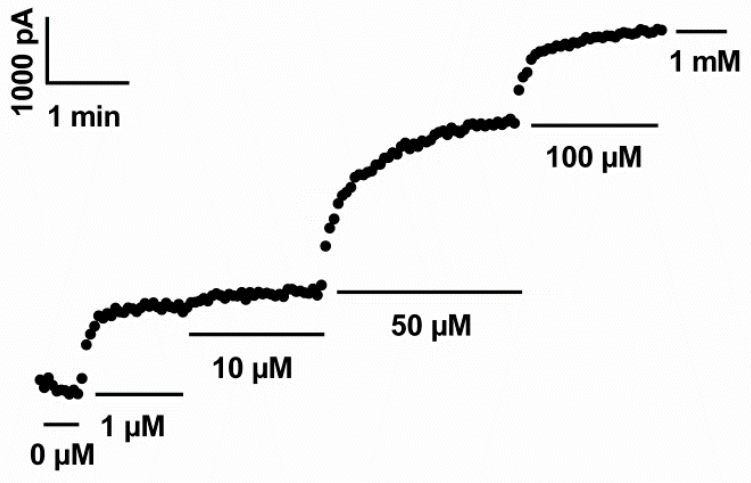

(b)

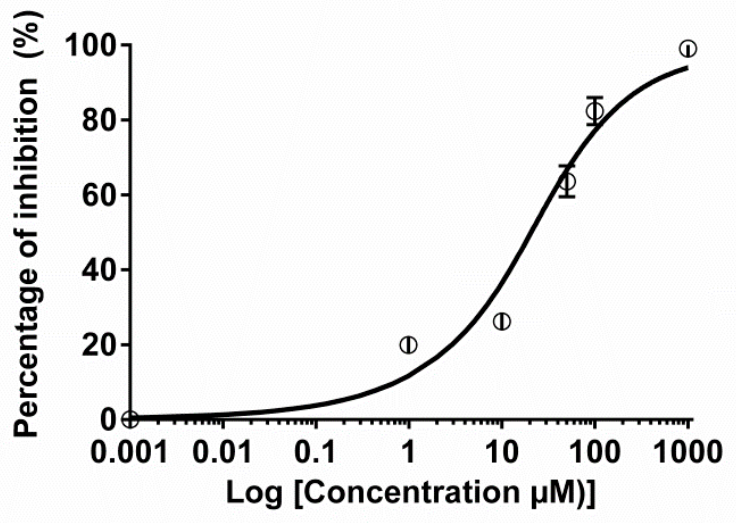

(d)

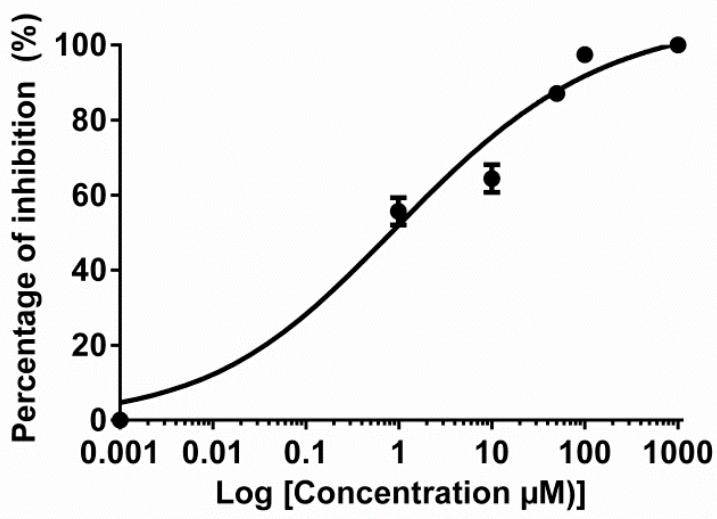

(f)

Figure 1. Pharmacological effects of Epigallocatechin-3-Gallate (EGCG) on the cardiac sodium channel $\mathrm{Na}_{\mathrm{v}}$ 1.5. (a) Chemical structure of EGCG. (b) Time course recording of the $\mathrm{I}_{\mathrm{Na}}$ current in the presence of various concentrations of EGCG. The dashed line represents the zero current. (c) Representative traces of $\mathrm{I}_{\mathrm{Na}}$ currents in the presence of various EGCG concentrations at holding potential $-100 \mathrm{mV}$. (d) Dose-response effects of EGCG on the inhibition of $\mathrm{I}_{\mathrm{Na}}$ peak currents (holding potential $=-100 \mathrm{mV}$, $\mathrm{IC}_{50}=31.2 \pm 3.6 \mu \mathrm{M}, n=8$ ). (e) Representative traces of $\mathrm{I}_{\mathrm{Na}}$ currents in the presence of various EGCG concentrations at holding potential $-80 \mathrm{mV}$. (f) Dose-response effects of EGCG on the inhibition of $\mathrm{I}_{\mathrm{Na}}$ peak currents (holding potential $=-80 \mathrm{mV}, \mathrm{IC}_{50}=2,1 \pm 1 \mu \mathrm{M}, n=5-7$ ). 


\subsection{Effect of EGCG on the Voltage-Dependence Properties of $N a_{v} 1.5$ Channels}

The second step of EGCG pharmacological characterization was to study the compound effect on $\mathrm{Na}_{\mathrm{v}} 1.5$ biophysics. For this aim, the voltage-dependence properties of $\mathrm{Na}_{\mathrm{v}} 1.5$ channels were investigated in the presence or absence of $30 \mu \mathrm{M}$ EGCG. The superfusion of this compound inhibited the cardiac sodium channels (Figure 2a,b, Table 1), induced a shift of steady-state inactivation towards more negative potentials (Figure 2c, Table 1), slowed the inactivation kinetics (Figure 3a,c, Table 1), and delayed the recovery from fast inactivation (Figure 3d, Table 1). Moreover, EGCG did not modify the voltage-dependence of activation but significantly affected the activation curve slope (Figure $2 \mathrm{~d}$, Table 1).

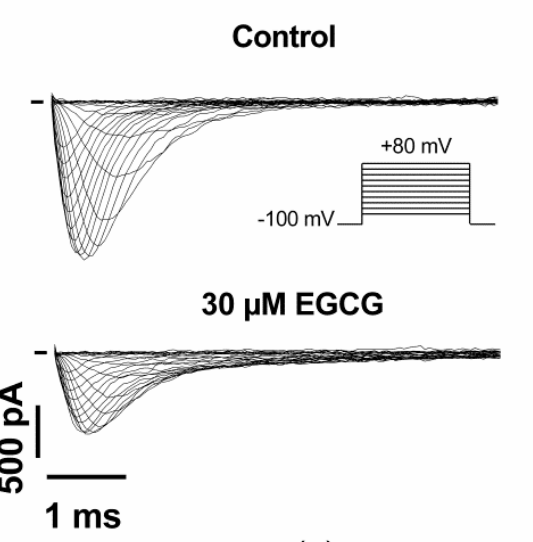

(a)

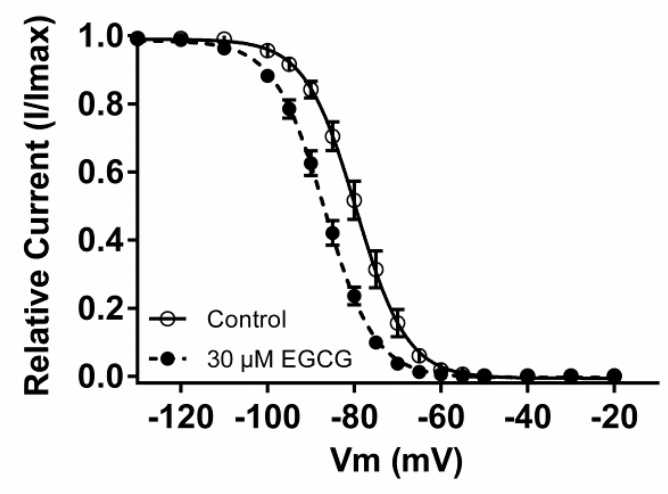

(c)

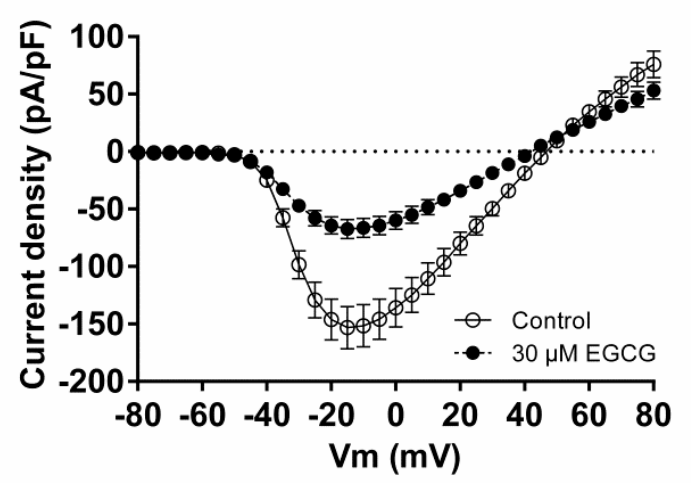

(b)

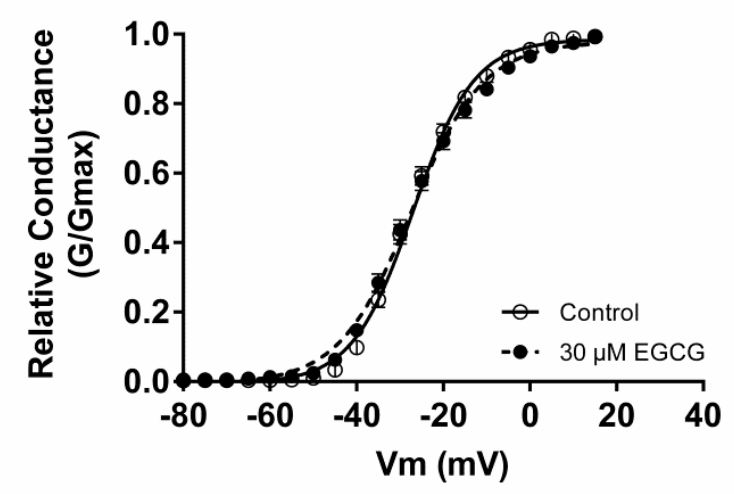

(d)

Figure 2. Effect of EGCG on the gating properties of $\mathrm{Na}_{\mathrm{v}} 1.5$ channels. (a) Representative traces of $\mathrm{I}_{\mathrm{Na}}$ current in the presence or the absence of $30 \mu \mathrm{M}$ of EGCG. (b) I/V relationship in the presence or the absence of EGCG. (c,d) Effect of EGCG on the voltage-dependence of inactivation and activation, respectively. 
Table 1. Effect of EGCG on the gating properties of $\mathrm{Na}_{\mathrm{v}} 1.5$ channels.

\begin{tabular}{lcc}
\hline & Control & 30 $\boldsymbol{\mu M}$ EGCG \\
\hline Peak current densities at $-20 \mathrm{mV}$ & $-146.2 \pm 17.8 ; n=12$ & $-64.3 \pm 7.3^{* * *} ; n=12$ \\
$(\mathrm{pA} / \mathrm{pF})$ & $-27.4 \pm 0.8 ; n=12$ & $-27.4 \pm 1 ; n=12$ \\
$\mathrm{~V}_{1 / 2}$ activation $(\mathrm{mV})$ & $6.7 \pm 0.2 ; n=12$ & $8 \pm 2^{* * *} ; n=12$ \\
Activation slope $(\mathrm{mV})$ & $1.12 \pm 0.02 ; n=12$ & $1.16 \pm 0.03 ; n=12$ \\
Time to peak at $-20 \mathrm{mV}(\mathrm{ms})$ & $-79.4 \pm 1.3 ; n=13$ & $-87 \pm 0.9^{* * *} ; n=13$ \\
$\mathrm{~V}_{1 / 2}$ inactivation $(\mathrm{mV})$ & $5 \pm 0.2 ; n=13$ & $5.5 \pm 0.2^{* *} ; n=13$ \\
Inactivation slope $(\mathrm{mV})$ & $0.43 \pm 0.02 ; n=12$ & $0.56 \pm 0.03^{* *} ; n=12$ \\
t1/2 inactivation at $-20 \mathrm{mV}(\mathrm{ms})$ & & \\
Recovery from fast inactivation $(\mathrm{ms})$ & $5.1 \pm 0.9 ; n=5$ & $24.3 \pm 7.1^{*} ; n=5$ \\
$\tau$ fast,1 & $110 \pm 28.6 ; n=5$ & $233.7 \pm 37.6^{*} ; n=5$ \\
$\tau$ fast,2 &
\end{tabular}

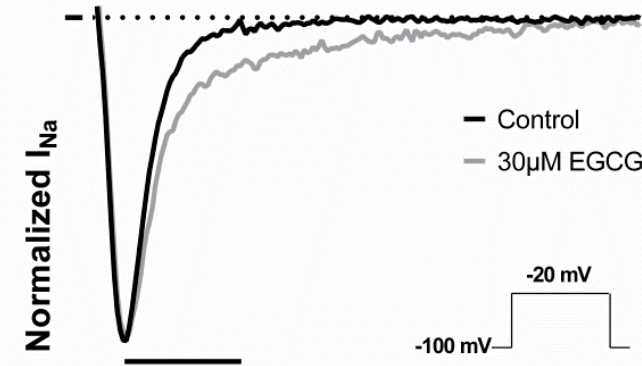

$2 \mathrm{~ms}$

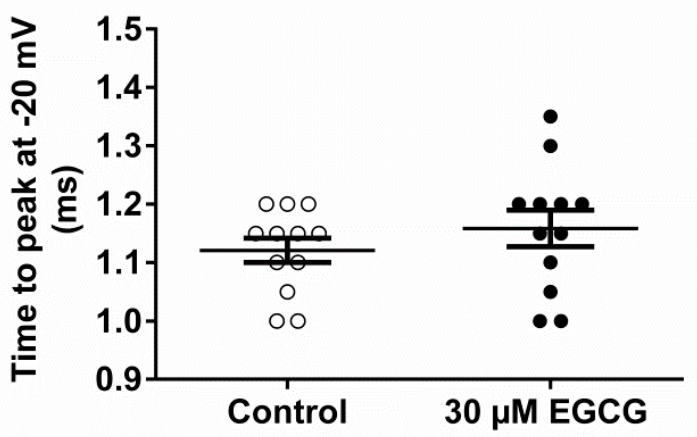

(b)

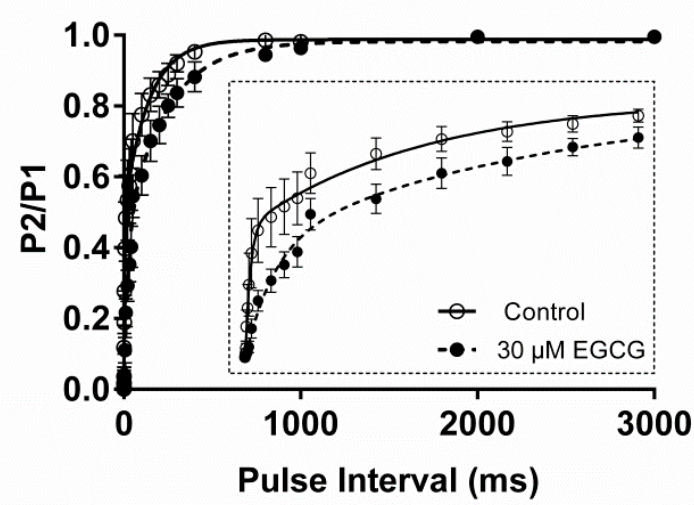

(d)

Figure 3. Effect of EGCG on $\mathrm{I}_{\mathrm{Na}}$ kinetics. (a) Representative traces of normalized $\mathrm{I}_{\mathrm{Na}}$ current in the presence or the absence of $30 \mu \mathrm{M}$ of EGCG. $\mathrm{I}_{\mathrm{Na}}$ currents were normalized to the maximal peak current measured, in each condition, at $-20 \mathrm{mV}$. EGCG effect on $\mathrm{I}_{\mathrm{Na}}$ time to peak (b), inactivation kinetics (c), and recovery from fast inactivation (d; inset, zoom on the interval between 0 and $300 \mathrm{~ms}$ ).

\subsection{EGCG did not Produce any Use-Dependent Blockade of $N a_{v} 1.5$ Channels}

To characterize the potential use-dependent block (UDB) of EGCG on $\mathrm{I}_{\mathrm{Na}}$ current, the effect of rapid pulsing on $\mathrm{Na}_{\mathrm{v}} 1.5$ was investigated via the application of a series of 5015 ms depolarizing pulses from -100 to $-20 \mathrm{mV}$ at various stimulation rates ( 1 and $10 \mathrm{~Hz}$ ). After the establishment of the whole-cell configuration, cells were allowed to stabilize before the first run of the UDB protocol in the 
absence of EGCG. Then, EGCG was perfused for $3 \mathrm{~min}$ while the membrane potential was held at $-100 \mathrm{mV}$, followed by the UDB protocol under $30 \mu \mathrm{M}$ EGCG.

After the application of EGCG, $\mathrm{I}_{\mathrm{Na}}$ currents were slightly but significantly reduced by $7 \%$ and $8 \%$ compared with the control when pulsing at 1 and $10 \mathrm{~Hz}$, respectively (Figure 4a,b, Table 2). These results suggest that there is little or no use-dependent blockade of EGCG on $\mathrm{Na}_{\mathrm{v}} 1.5$ related currents.

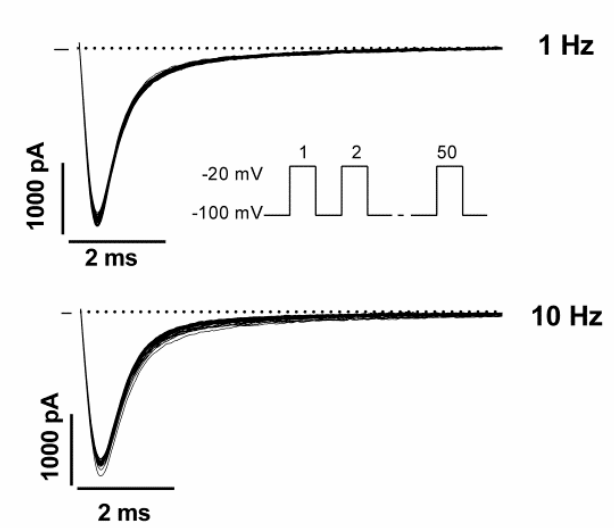

(a)

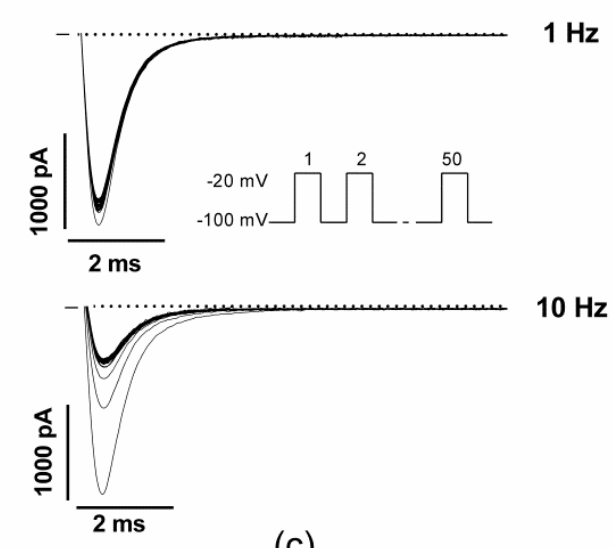

(c)

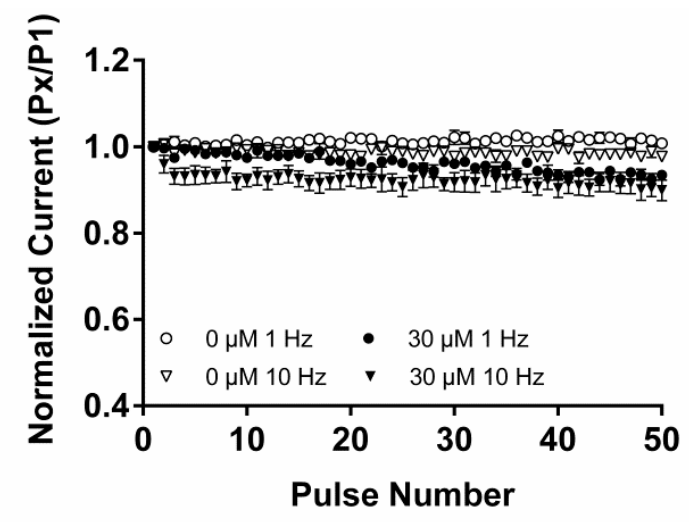

(b)

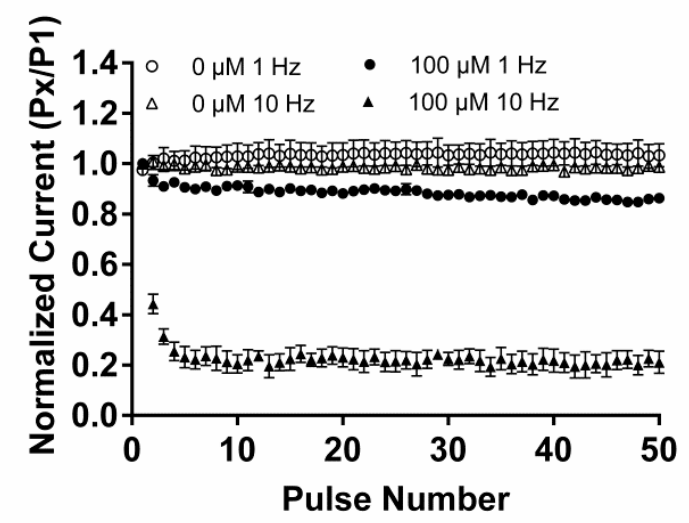

(d)

Figure 4. Use-dependent block protocol in the presence or absence of $30 \mu \mathrm{M}$ EGCG. (a) Representative trace of $\mathrm{I}_{\mathrm{Na}}$ currents at 1 and $10 \mathrm{~Hz}$ in the presence of $30 \mu \mathrm{M}$ of EGCG. (b) Normalized $\mathrm{I}_{\mathrm{Na}}$ current versus pulse number in the presence or absence of $30 \mu \mathrm{M}$ of EGCG at 1 and $10 \mathrm{~Hz}$. (c) Representative trace of $\mathrm{I}_{\mathrm{Na}}$ currents at 1 and $10 \mathrm{~Hz}$ in the presence of $100 \mu \mathrm{M}$ of Mexiletine. (d) Normalized $\mathrm{I}_{\mathrm{Na}}$ current versus pulse number in the presence or absence of $100 \mu \mathrm{M}$ of mexiletine at 1 and $10 \mathrm{~Hz}$.

Table 2. Characterization of the use-dependent block of EGCG.

\begin{tabular}{lcc}
\hline & UDB-1 Hz & UDB-10 Hz \\
\hline EGCG $(30 \mu \mathrm{M})$ & $0.93 \pm 0.01^{* *}, n=5$ & $0.90 \pm 0.02{ }^{*}, n=5$ \\
Mexiletine $(100 \mu \mathrm{M})$ & $0.86 \pm 0.01^{* * *}, n=4$ & $0.21 \pm 0.04^{* * *}, n=4$ \\
\hline \multicolumn{3}{l}{$p<0.05,{ }^{* *} p<0.01,{ }^{* * *} p<0.001$ versus control. }
\end{tabular}

To validate our experimental conditions, especially the used UDB protocol, mexiletine has been used as a positive control. As shown in Figure $4 \mathrm{c}, \mathrm{d}$, the application of $100 \mu \mathrm{M}$ mexiletine significantly reduces the $\mathrm{I}_{\mathrm{Na}}$ current by $17 \%$ and $77 \%$ compared with the control when pulsing at 1 and $10 \mathrm{~Hz}$, respectively. These findings demonstrated the ability of the applied UDB protocol to characterize the use-dependent block of a given drug. 


\subsection{Simulations Suggest that EGCG does not Spontaneously Permeate Cell Membranes}

To obtain a first insight into the mechanism through which EGCG may exert its effect on $\mathrm{Na}_{\mathrm{v}} 1.5$, the interaction between EGCG and a model lipid membrane that mimics the environment in which $\mathrm{Na}_{\mathrm{v}} 1.5$ is found, was characterized. To this effect, molecular dynamics (MD) simulations of a system containing EGCG initially positioned at the center of a 1-palmitoyl-2-oleoyl-sn-glycero-3-phosphocholine (POPC) bilayer, were carried out. Molecular dynamics simulations enable us to investigate the time-dependent dynamical and structural properties of systems at the atomistic level. Three $1 \mu$ simulations suggested that EGCG did not preferentially stay in the center of the bilayer, but that it spontaneously and consistently relocated to the membrane headgroup region (Figure 5). Over the course of the simulations, no signs of spontaneous crossing from one leaflet to the other were observed, indicative of a relatively large free energy barrier associated with EGCG transport across the membrane, that is not easily crossed on the microsecond timescale. This finding is consistent with the molecule's amphiphilic nature. These results indicate that EGCG may not spontaneously permeate the membrane and become able to block the $\mathrm{Na}_{\mathrm{v}} 1.5$ channel via the entrance to the internal cavity via the inner pore mouth.
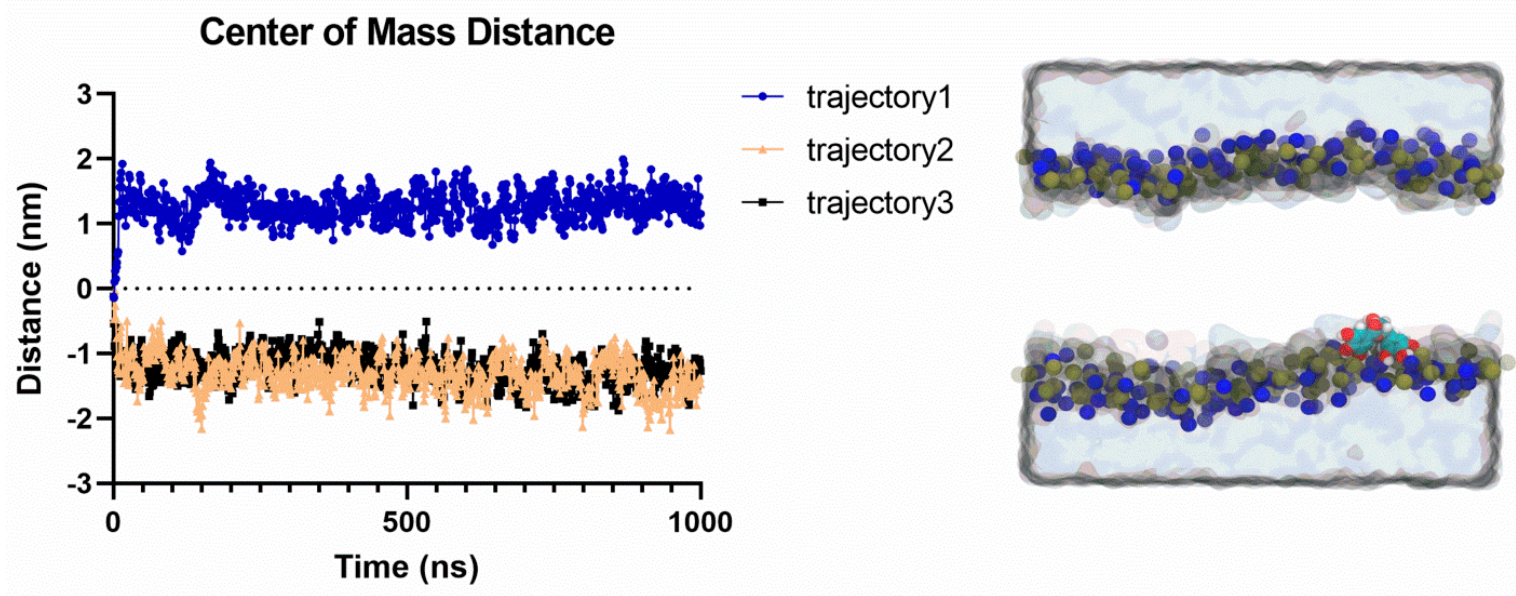

(a)

(b)

Figure 5. Molecular dynamics simulations show the preferential localization of EGCG in the headgroup region of a POPC membrane. (a) Localization of EGCG molecules along 1-microsecond simulation runs with respect to the bilayer center $(0 \mathrm{~nm})$. (b) Representative snapshot highlighting the preferential localization of the EGCG in the headgroup region of a POPC bilayer (phosphate and nitrogen atoms are shown as blue and brown spheres, respectively, the solution is shown as a grey surface and lipid tails are omitted for clarity. The EGCG molecule is shown as cyan, red, and white spheres).

\section{Discussion}

The present study aimed to characterize the biophysical mechanism underlying the EGCG effect on the cardiac sodium channel $\mathrm{Na}_{\mathrm{v}} 1.5$.

Our results showed that EGCG inhibited the $\mathrm{I}_{\mathrm{Na}}$ current in a concentration-dependent manner either at a holding potential of -100 or at $-80 \mathrm{mV}$. The $\mathrm{IC}_{50}$ of EGCG was much lower at a holding potential of $-80 \mathrm{mV}$ compared to $-100 \mathrm{mV},\left(\mathrm{IC}_{50}=32.4 \pm 3.6 \mu \mathrm{M}\right.$ and $2.1 \pm 1 \mu \mathrm{M}$ at $-100 \mathrm{mV}$ and -80 $\mathrm{mV}$, respectively). This demonstrates that the membrane holding potential affects the affinity of EGCG to $\mathrm{Na}_{\mathrm{v}} 1.5$, suggesting that EGCG interacts with a higher affinity to the inactivated state of the cardiac sodium channel. Similar results have been reported by Kang et al., showing a dose and state-dependent inhibition of $\mathrm{I}_{\mathrm{Na}}$ current in the presence of EGCG [30]. However, the obtained $\mathrm{IC}_{50}$ were different from those published by these authors $(100 \mu \mathrm{M}$ and $24.6 \mu \mathrm{M}$ at holding potentials of $-90 \mathrm{mV}$ and $-70 \mathrm{mV}$, respectively [30]). These discrepancies are likely related to different experimental conditions used in the two studies. Kang et al., have stably transfected $\mathrm{Na}_{\mathrm{v}} 1.5$ in HEK293 cells in the absence of its 
regulatory subunit $\mathrm{Na}_{\mathrm{v}}-\beta 1$, investigated the pharmacological effect of ECGC at $35^{\circ} \mathrm{C}$, and used -90 or $-70 \mathrm{mV}$ as holding potentials to generate $\mathrm{I}_{\mathrm{Na}}$ currents. In contrast to these conditions, we have transiently transfected tsA-201 cells with $\mathrm{Na}_{\mathrm{v}} 1.5$ in the presence of $\mathrm{Na}_{\mathrm{v}}-\beta 1$, recorded $\mathrm{I}_{\mathrm{Na}}$ currents at room temperature $\left(23-25^{\circ} \mathrm{C}\right)$, and used -100 or $-80 \mathrm{mV}$ as holding potentials to generate $\mathrm{I}_{\mathrm{Na}}$ currents. These protocol changes may induce noticeable differences. Indeed, since $\mathrm{Na}_{\mathrm{v}}-\beta \mathrm{s}$ are strong modulators of $\mathrm{Na}_{\mathrm{v}} 1.5$ electrophysiological properties [14], the sensitivity of the cardiac sodium channel towards EGCG may be affected by the presence or absence of $\mathrm{Na}_{\mathrm{v}}-\beta 1$. Furthermore, conducting experiments at elevated temperatures may induce the degradation of EGCG and its epimerization to gallocatechin-3-gallate (GCG) [31], which could trigger different biophysical modifications of $\mathrm{I}_{\mathrm{Na}}$ current as it was shown in rat dorsal root ganglion neurons [32]. On the other hand, under the same conditions, the activity of EGCG on $\mathrm{Na}_{\mathrm{v}} 1.5$ could be altered as it was described for other $\mathrm{I}_{\mathrm{Na}}$ inhibitors such as flecainide, ajmaline, and ranolazine [33,34].

The biophysical mechanism of $\mathrm{Na}_{\mathrm{v}} 1.5$ inhibition by EGCG was further investigated by characterizing the biophysical gating properties of these channels in the presence of $30 \mu \mathrm{M}$ EGCG. Under these conditions, EGCG shifts the voltage-dependence of inactivation curve toward more negative potentials by $7.6 \mathrm{mV}$, slows the inactivation kinetics, and delays the recovery from fast inactivation, indicating that EGCG binds to the inactivated state of $\mathrm{Na}_{\mathrm{v}} 1.5$. However, EGCG had no effect on the voltage-dependence of activation and significantly affected the activation curve slope. The modification of the activation slope may be caused by a more efficient clamp of the membrane potential in the presence of $30 \mu \mathrm{M}$ EGCG. Indeed, even with optimal compensation for series resistance (Rs), the remaining uncompensated Rs combined with large and rapid $\mathrm{I}_{\mathrm{Na}}$ currents let a voltage error that could produce a loss of the voltage clamp. Thus, a reduced sodium current magnitude, as it has been noticed in the presence of EGCG, could decrease the resulting series resistance error and improve the voltage clamp quality.

On the other hand, the observed shift of the steady-state of inactivation is consistent with what has been previously described for $\mathrm{Na}_{\mathrm{v}} 1.5$ [30]. One should note that the EGCG effects on the other biophysical properties were mainly investigated on the neuronal $\mathrm{Na}_{\mathrm{v}}$ channels $[32,35,36]$. These published results are in concordance with the EGCG effect on the fast inactivation kinetics, and recovery from inactivation of the cardiac sodium channels.

With regards to the activation process, Kim et al. observed that $1 \mu \mathrm{M}$ EGCG did not affect the voltage-dependence of activation of tetrodotoxin-sensitive and resistant $\mathrm{I}_{\mathrm{Na}}$ currents in rat dorsal root ganglion neurons [36], which was consistent with the results of the present study studying the cardiac sodium current. In contrast, Deng et al. showed a negative shift of the activation curve in the presence of EGCG in primary cultures of rat hippocampal neurons [35]. From our perspective, these discrepancies could be related to the quality of the membrane potential clamp. Indeed, based on the sodium current traces presented in Deng's study, a sub-optimal voltage-clamp quality of these currents is observed, which makes any interpretation difficult [35].

Furthermore, our investigations suggested that there is little or no use-dependent block of EGCG on $\mathrm{Na}_{\mathrm{v}}$ 1.5. The absence of the UDB could be explained by the slight modification of the recovery from fast inactivation. Indeed, in the presence of EGCG, the almost "normal" recovery from fast inactivation prevents an additional progressive accumulation of inactivated $\mathrm{Na}_{\mathrm{v}} 1.5$, which represents the preferential binding state of EGCG. These findings are consistent with those obtained in other studies testing the effect of gallocatechin-3-gallate on the tetrodotoxin-resistant voltage-gated sodium channels in rat dorsal root ganglion neurons [32].

In a first attempt to characterize the molecular mechanism through which EGCG may exert its effect on $\mathrm{Na}_{\mathrm{v}} 1.5$, we investigated how EGCG interacts with the lipidic environment surrounding $\mathrm{Na}_{\mathrm{v}}$ 1.5. Indeed, relatively hydrophobic compounds such as EGCG have been hypothesized to act on membrane proteins either via direct interaction, via the effect on the membrane, or both. Voltage-gated sodium channels, in particular, have fenestrations lining their pore domain, which enable modulators to access the pore via the membrane. We thus sought to gain a first insight into how $\mathrm{Na}_{\mathrm{v}}$ channels 
may be modulated by EGCG by characterizing where this compound localized preferentially in a membrane. This was done by carrying out MD simulations, which provided a detailed atomistic view of the behavior of EGCG when it was placed in a model lipidic membrane: Calculations were initiated with EGCG located at the center of the POPC bilayer. The obtained results suggest that EGCG is spontaneously relocated to the membrane headgroup region.

The predicted re-localization of EGCG to the membrane head group is consistent with the results of Salazar et al., which have demonstrated that EGCG modifies the activity of a membrane-bound protein upon binding to the phospholipid head groups of the red blood cell membranes [37]. Similarly, Ingólfsson et al. have shown that the biological effects of green tea catechins could be attributed to multiple molecular interactions because the catechins accumulate at the bilayer/solution interface and modify bilayer properties that can influence gramicidin channel function [38]. However, MD simulations results cannot exclude the possibility that EGCG exerts its biophysical effect via access to its binding site, on $\mathrm{Na}_{\mathrm{v}} 1.5$, through the cell membrane. Indeed, as shown for local anesthetics and antiarrhythmic drugs [39], the EGCG blocking effect could also be controlled by the channel's fenestrations.

The current findings support the hypothesis that EGCG could be used as an anti-arrhythmic drug in the setting of $\mathrm{Na}_{\mathrm{v}} 1.5$ gain-of-function mutations; as has been suggested by Boukhabza et al. These authors have predicted that EGCG may limit the cardiac cells hyperexcitability related to the presence of $\mathrm{Na}_{\mathrm{v}} 1.5-\mathrm{R} 222 \mathrm{Q}$ and $\mathrm{Na}_{\mathrm{v}}$ 1.5-I141V mutants [20]. On the other hand, the present study demonstrated that the membrane holding potential affects the affinity of EGCG to $\mathrm{Na}_{\mathrm{v}} 1.5$, suggesting that EGCG interacts with a higher affinity to the inactivated state of the cardiac sodium channel. Thus, we could expect an atrial-selective block of $\mathrm{Na}_{\mathrm{v}} 1.5$ channels due to a more depolarized resting membrane potential in the atria compared to the ventricles. Then, a higher beneficial effect of EGCG could be observed in the setting of atrial hyperexcitability phenotypes.

Nonetheless, it remains somehow challenging to interpret the clinical relevance of our results even in the context of cardiac hyperexcitability phenotypes. Many in vitro studies have shown that the effective concentrations of EGCG to target relevant pathophysiological pathways are typically ranged from 1 to $1000 \mu \mathrm{mol} / \mathrm{L}$. However, the pharmacological disposition of EGCG in humans indicates that its serum concentration is in the nanomolar scale [40-48]. In addition, EGCG is well known for its chemical instability under physiological conditions due to its easy degradation and metabolism $[31,49,50]$. Therefore, any potential impact of EGCG intake may reflect the combined effects of EGCG and its metabolites.

In conclusion, the present study suggests that EGCG may modulate the biophysical properties of $\mathrm{Na}_{\mathrm{v}} 1.5$ via access to its binding site through the cell membrane or via a bilayer-mediated mechanism. These results constitute a first step towards the characterization of the biophysical mechanism underlying the inhibitory action of EGCG on $\mathrm{Na}_{\mathrm{v}} 1.5$. However, the exact molecular interactions underlying these effects are still unknown and remain to be studied.

\section{Materials and Methods}

\subsection{Cell Culture and Transfection}

TsA-201 cells were cultured at $37^{\circ} \mathrm{C}$ in Dulbecco's Modified Eagle Medium (DMEM) supplemented with $10 \%$ Fetal Bovine Serum (FBS), $4 \mathrm{mM}$ glutamine, and a cocktail of streptomycin-penicillin antibiotics in a humidified atmosphere of $5 \% \mathrm{CO}_{2}$ and $95 \%$ air. All cell medium components, except glutamine (Sigma-Aldrich), were purchased from Gibco (Fisher Scientific, Zurich, Switzerland).

For electrophysiological experiments, tsA-201 cells were transiently transfected with DNA complexed to JetPEI (Polyplus-transfection) according to the manufacturer's instructions. DNA concentrations were $1 \mu \mathrm{g}$ of $\mathrm{pCDN} 3.1-\mathrm{Na}_{\mathrm{v}} 1.5$ and $1 \mu \mathrm{g}$ of pIRES-h $\beta 1-C D 8$. The resulting $\mathrm{Na}_{\mathrm{v}} 1.5$ protein was a splice variant lacking glutamine at position 1077 (Q1077del). Eight hours after transfection, the cells were isolated and seeded in plastic Petri dishes at low density. 


\subsection{Cellular Electrophysiology}

Twenty-four hours after transfection, the resulting sodium current $\left(\mathrm{I}_{\mathrm{Na}}\right)$ was recorded at room temperature $\left(23-25^{\circ} \mathrm{C}\right)$, under whole-cell voltage-clamp conditions with Axon PClamp 10 software through an A/D converter (Digidata 1440A) using an Axopatch 200B (all Axon Instruments Molecular Devices Corp., CA, USA). Series resistances were compensated (up to $90 \%$ compensation), and the residual capacitive currents were canceled using a $\mathrm{P} / 4$ protocol. The cells were bathed with an extracellular solution containing (in mmol/L): $\mathrm{NaCl} 50$, NMDG-Cl 80, CsCl 5, $\mathrm{MgCl}_{2} 1.2, \mathrm{CaCl}_{2}$ 2, HEPES 10, glucose 5. The $\mathrm{pH}$ was adjusted to 7.4 with $\mathrm{CsOH}$. Glass pipettes (tip resistance: 1.5 to 3 $\mathrm{M} \Omega$ ) were filled with an intracellular medium containing (in mmol/L): $\mathrm{Na}_{2} \mathrm{ATP} 5, \mathrm{CsAsp} 70, \mathrm{CsCl} 60$, EGTA 11, $\mathrm{CaCl}_{2} 1, \mathrm{MgCl}_{2}$ 1, HEPES 10. $\mathrm{pH}$ was adjusted to 7.2 with $\mathrm{CsOH}$.

Activation properties of $\mathrm{Na}_{\mathrm{v}} 1.5$ channels were determined from I/V relationships by normalizing the sodium current peak to the driving force. Steady-state inactivation was measured with a standard double-pulse protocol. Cells were held at $-100 \mathrm{mV}$ before the application of $500 \mathrm{~ms}$ conditioning pulses, ranging from -130 to $-20 \mathrm{mV}$. Then, a $20 \mathrm{~ms}$ test pulse to $-20 \mathrm{mV}$ was applied. The measured current was then normalized to the maximum peak current recorded after conditioning pulses (I/Imax) and plotted as a function of conditioning step voltage. Activation and inactivation curves were fit to a Boltzmann equation.

For the pharmacological investigation, the peak current amplitudes at different EGCG concentrations were subtracted from the current obtained with the control solution and were normalized to the control value:

$$
\text { Inhibition Percentage }(\%)=[(\text { Icontrol }- \text { IEGCG }) / \text { Icontrol }] \times 100
$$

$\mathrm{IC}_{50}$ was calculated according to Quest GraphTM IC ${ }_{50}$ Calculator (Quest GraphTM IC50 Calculator). AAT Bioquest, Inc., 24 Apr. 2019, https://www.aatbio.com/tools/ic50-calculator).

\subsection{Chemicals}

Epigallocatechin-3-Gallate (EGCG, Sigma-Aldrich, CAS Number 989-51-5) was dissolved directly into the external solutions. Fresh EGCG solutions were prepared before each experiment. During the same day, EGCG solutions were renewed every $5 \mathrm{~h}$ to avoid compound degradation (e.g., brown discoloration of solutions).

\subsection{Molecular Dynamics Simulations}

The 3D structure of the EGCG molecule was obtained from PubChem Database $((-)$-Epigallocatechin gallate, CID $=65064)$. The system containing an EGCG molecule placed at the center of a 1-palmitoyl-2-oleoyl-sn-glycero-3-phosphocholine membrane and plunged in a $0.1 \mathrm{M}$ $\mathrm{NaCl}$ solution was prepared using the CHARMM-GUI server [51-53]. The lipid and ions interactions were described using the CHARMM36 (Chemistry at Harvard Macromolecular Mechanics) force field [54], whereas water molecules were modeled using the TIP3P model [55]. Simulations were performed using the NPT ensemble, where the temperature and the pressure were maintained at $310 \mathrm{~K}$ and $1 \mathrm{~atm}$, respectively, using Parinello-Rahaman pressure coupling [56] and Nose-Hoover temperature coupling [57]. The cut-off value used to compute non-bonded interactions was set to $12 \AA$ and long-range electrostatic interactions were computed using the particle mesh Ewald method [58]. Three replicas $1 \mu \mathrm{s}$ simulations were run using the GROMACS package version 2018.4 on our local high-performance computing cluster [59]. Distances between the COM (Center of Mass) of EGCG and the membrane were calculated by using the gmx distance analysis tool of GROMACS. EGCG was parameterized using the SWISS-PARAM software [60]. 


\subsection{Data Analysis and Statistical Methods}

Currents were analyzed with Clampfit software (Axon Instruments, San Jose, CA, USA). Data were analyzed using a combination of pClamp10, Excel (Microsoft), Igor Pro (WaveMetrics), and Prism (graphpad).

Comparisons between groups were performed with a two-tailed paired Student's t-test. Data were expressed as mean \pm SEM. A $p$-value $<0.05$ was considered significant.

\section{Conclusions}

In the current study, we have characterized the effect of epigallocatechin-3-gallate on the cardiac sodium channel. This compound shows a higher affinity for the inactivated state of $\mathrm{Na}_{\mathrm{V}} 1.5$ without any effect on its activation process. In addition, molecular dynamics simulations have predicted the re-localization of EGCG to the membrane headgroup region, suggesting that EGCG may not spontaneously permeate the cell membrane and may exert it effects on $\mathrm{Na}_{\mathrm{v}} 1.5$ by a bilayer mediated mechanism.

Supplementary Materials: The following are available online, Figure S1: EGCG dose-dependent effect on the fast inactivation kinetics. (a) Representative traces of normalized $\mathrm{I}_{\mathrm{Na}}$ current in the presence of various EGCG concentrations. (b) EGCG effect on $\mathrm{I}_{\mathrm{Na}}$ inactivation kinetics.

Author Contributions: Conceptualization, M.-Y.A. and H.A.; methodology, M.-Y.A., L.D., and H.A; software, H.K., M.-Y.A., and L.D.; validation, M.-Y.A., L.D., and H.A.; formal analysis, M.-Y.A. and L.D.; investigation, H.K., M.-Y.A., and L.D.; resources, H.A.; data curation, M.-Y.A. and L.D.; writing-original draft preparation, H.K., M.-Y.A., L.D., and H.A.; writing—review and editing, H.K., M.-Y.A., L.D., and H.A.; visualization, M.-Y.A.; supervision, M.-Y.A. and H.A.; project administration, M.-Y.A. and H.A.; funding acquisition, M.-Y.A. and H.A. All authors have read and agreed to the published version of the manuscript.

Funding: This research was funded by the leading House from the Middle East and North Africa, Switzerland, grant number Seed Money 2018 -09.

Acknowledgments: The authors gratefully acknowledge Jean-Sébastien Rougier and Maria Essers, Institute of Biochemistry and Molecular Medicine, University of Bern; and Marina Kasimova, Science for Life Laboratory, Department of Applied Physics, KTH Royal Institute of Technology, Solna, Sweden, for their support. L.D. acknowledges support from SciLifeLab. The MD simulations were performed on resources provided by the Swedish National Infrastructure for Computing (SNIC) at PDC Centre for High-Performance Computing (PDC-HPC).

Conflicts of Interest: The authors declare no conflict of interest.

\section{References}

1. Chevalier, M.; Vermij, S.H.; Wyler, K.; Gillet, L.; Keller, I.; Abriel, H. Transcriptomic analyses of murine ventricular cardiomyocytes. Sci. Data 2018, 5, 180170. [CrossRef] [PubMed]

2. Naylor, C.E.; Bagneris, C.; DeCaen, P.G.; Sula, A.; Scaglione, A.; Clapham, D.E.; Wallace, B.A. Molecular basis of ion permeability in a voltage-gated sodium channel. Embo J. 2016, 35, 820-830. [CrossRef] [PubMed]

3. Payandeh, J.; Scheuer, T.; Zheng, N.; Catterall, W.A. The crystal structure of a voltage-gated sodium channel. Nature 2011, 475, 353-358. [CrossRef] [PubMed]

4. Savio-Galimberti, E.; Argenziano, M.; Antzelevitch, C. Cardiac Arrhythmias Related to Sodium Channel Dysfunction. Handb. Exp. Pharmacol. 2018, 246, 331-354. [CrossRef]

5. Wilde, A.A.M.; Amin, A.S. Clinical Spectrum of SCN5A Mutations: Long QT Syndrome, Brugada Syndrome, and Cardiomyopathy. Jacc. Clin. Electrophysiol. 2018, 4, 569-579. [CrossRef]

6. Laurent, G.; Saal, S.; Amarouch, M.Y.; Beziau, D.M.; Marsman, R.F.; Faivre, L.; Barc, J.; Dina, C.; Bertaux, G.; Barthez, O.; et al. Multifocal ectopic Purkinje-related premature contractions: A new SCN5A-related cardiac channelopathy. J. Am. Coll. Cardiol. 2012, 60, 144-156. [CrossRef]

7. Swan, H.; Amarouch, M.Y.; Leinonen, J.; Marjamaa, A.; Kucera, J.P.; Laitinen-Forsblom, P.J.; Lahtinen, A.M.; Palotie, A.; Kontula, K.; Toivonen, L.; et al. Gain-of-function mutation of the SCN5A gene causes exercise-induced polymorphic ventricular arrhythmias. Circ. Cardiovasc. Genet. 2014, 7, 771-781. [CrossRef]

8. Yu, S.; Li, G.; Huang, C.L.; Lei, M.; Wu, L. Late sodium current associated cardiac electrophysiological and mechanical dysfunction. Pflug. Arch. Eur. J. Physiol. 2018, 470, 461-469. [CrossRef] 
9. Mann, S.A.; Castro, M.L.; Ohanian, M.; Guo, G.; Zodgekar, P.; Sheu, A.; Stockhammer, K.; Thompson, T.; Playford, D.; Subbiah, R.; et al. R222Q SCN5A mutation is associated with reversible ventricular ectopy and dilated cardiomyopathy. J. Am. Coll. Cardiol. 2012, 60, 1566-1573. [CrossRef]

10. Amarouch, M.Y.; Swan, H.; Leinonen, J.; Marjamaa, A.; Lahtinen, A.M.; Kontula, K.; Toivonen, L.; Widen, E.; Abriel, H. Antiarrhythmic Action of Flecainide in Polymorphic Ventricular Arrhythmias Caused by a Gain-of-Function Mutation in the Nav 1.5 Sodium Channel. Ann. Noninvasive Electrocardiol. 2016, 21, 343-351. [CrossRef]

11. Amarouch, M.Y.; Abriel, H. Cellular hyper-excitability caused by mutations that alter the activation process of voltage-gated sodium channels. Front. Physiol. 2015, 6, 45. [CrossRef] [PubMed]

12. Saber, S.; Amarouch, M.Y.; Fazelifar, A.F.; Haghjoo, M.; Emkanjoo, Z.; Alizadeh, A.; Houshmand, M.; Gavrilenko, A.V.; Abriel, H.; Zaklyazminskaya, E.V. Complex genetic background in a large family with Brugada syndrome. Physiol. Rep. 2015, 3. [CrossRef] [PubMed]

13. Kyle, J.W.; Makielski, J.C. Diseases caused by mutations in Nav1.5 interacting proteins. Card. Electrophysiol. Clin. 2014, 6, 797-809. [CrossRef] [PubMed]

14. Edokobi, N.; Isom, L.L. Voltage-Gated Sodium Channel beta1/beta1B Subunits Regulate Cardiac Physiology and Pathophysiology. Front. Physiol. 2018, 9, 351. [CrossRef] [PubMed]

15. Salvarani, N.; Crasto, S.; Miragoli, M.; Bertero, A.; Paulis, M.; Kunderfranco, P.; Serio, S.; Forni, A.; Lucarelli, C.; Dal Ferro, M.; et al. The K219T-Lamin mutation induces conduction defects through epigenetic inhibition of SCN5A in human cardiac laminopathy. Nat. Commun. 2019, 10, 2267. [CrossRef] [PubMed]

16. Cerrone, M.; Lin, X.; Zhang, M.; Agullo-Pascual, E.; Pfenniger, A.; Chkourko Gusky, H.; Novelli, V.; Kim, C.; Tirasawadichai, T.; Judge, D.P.; et al. Missense mutations in plakophilin-2 cause sodium current deficit and associate with a Brugada syndrome phenotype. Circulation 2014, 129, 1092-1103. [CrossRef] [PubMed]

17. Neubauer, J.; Rougier, J.S.; Abriel, H.; Haas, C. Functional implications of a rare variant in the sodium channel beta1B subunit (SCN1B) in a 5-month-old male sudden infant death syndrome case. Heartrhythm Case Rep. 2018, 4, 187-190. [CrossRef]

18. Van Hoeijen, D.A.; Blom, M.T.; Tan, H.L. Cardiac sodium channels and inherited electrophysiological disorders: An update on the pharmacotherapy. Expert Opin. Pharmacother. 2014, 15, 1875-1887. [CrossRef]

19. Mankad, P.; Kalahasty, G. Antiarrhythmic Drugs: Risks and Benefits. Med Clin. North. Am. 2019, 103, 821-834. [CrossRef]

20. Boukhabza, M.; El Hilaly, J.; Attiya, N.; El-Haidani, A.; Filali-Zegzouti, Y.; Mazouzi, D.; Amarouch, M.Y. In Silico Evaluation of the Potential Antiarrhythmic Effect of Epigallocatechin-3-Gallate on Cardiac Channelopathies. Comput. Math. Methods Med. 2016, 2016, 7861653. [CrossRef]

21. Chang, J.H.; Chang, S.L.; Hong, P.D.; Chen, P.N.; Hsu, C.H.; Lu, Y.Y.; Chen, Y.C. Epigallocatechin-3-gallate modulates arrhythmogenic activity and calcium homeostasis of left atrium. Int. J. Cardiol. 2017, 236, 174-180. [CrossRef] [PubMed]

22. Eng, Q.Y.; Thanikachalam, P.V.; Ramamurthy, S. Molecular understanding of Epigallocatechin gallate (EGCG) in cardiovascular and metabolic diseases. J. Ethnopharmacol. 2018, 210, 296-310. [CrossRef] [PubMed]

23. Kuriyama, S.; Shimazu, T.; Ohmori, K.; Kikuchi, N.; Nakaya, N.; Nishino, Y.; Tsubono, Y.; Tsuji, I. Green tea consumption and mortality due to cardiovascular disease, cancer, and all causes in Japan: The Ohsaki study. Jama 2006, 296, 1255-1265. [CrossRef] [PubMed]

24. Suzuki, J.; Ogawa, M.; Maejima, Y.; Isobe, K.; Tanaka, H.; Sagesaka, Y.M.; Isobe, M. Tea catechins attenuate chronic ventricular remodeling after myocardial ischemia in rats. J. Mol. Cell. Cardiol. 2007, 42, 432-440. [CrossRef]

25. Suzuki, J.; Ogawa, M.; Futamatsu, H.; Kosuge, H.; Sagesaka, Y.M.; Isobe, M. Tea catechins improve left ventricular dysfunction, suppress myocardial inflammation and fibrosis, and alter cytokine expression in rat autoimmune myocarditis. Eur. J. Heart Fail. 2007, 9, 152-159. [CrossRef]

26. Ma, Y.; Hu, Y.; Wu, J.; Wen, J.; Li, S.; Zhang, L.; Zhang, J.; Li, Y.; Li, J. Epigallocatechin-3-gallate inhibits angiotensin II-induced cardiomyocyte hypertrophy via regulating Hippo signaling pathway in H9c2 rat cardiomyocytes. Acta Biochim. Et Biophys. Sin. 2019, 51, 422-430. [CrossRef]

27. Al Hroob, A.M.; Abukhalil, M.H.; Hussein, O.E.; Mahmoud, A.M. Pathophysiological mechanisms of diabetic cardiomyopathy and the therapeutic potential of epigallocatechin-3-gallate. Biomed. Pharmacother. 2019, 109, 2155-2172. [CrossRef] 
28. Zhang, Q.; Hu, L.; Chen, L.; Li, H.; Wu, J.; Liu, W.; Zhang, M.; Yan, G. (-)-Epigallocatechin-3-gallate, the major green tea catechin, regulates the desensitization of beta1 adrenoceptor via GRK2 in experimental heart failure. Inflammopharmacology 2018, 26, 1081-1091. [CrossRef]

29. Wei, H.; Meng, Z. Epigallocatechin-3-gallate protects Na+ channels in rat ventricular myocytes against sulfite. Cardiovasc. Toxicol. 2010, 10, 166-173. [CrossRef]

30. Kang, J.; Cheng, H.; Ji, J.; Incardona, J.; Rampe, D. In vitro electrocardiographic and cardiac ion channel effects of (-)-epigallocatechin-3-gallate, the main catechin of green tea. J. Pharmacol. Exp. Ther. 2010, 334, 619-626. [CrossRef]

31. Wang, R.; Zhou, W.; Jiang, X. Reaction kinetics of degradation and epimerization of epigallocatechin gallate (EGCG) in aqueous system over a wide temperature range. J. Agric. Food Chem. 2008, 56, 2694-2701. [CrossRef] [PubMed]

32. Zhang, Y.; Jia, Y.Y.; Guo, J.L.; Liu, P.Q.; Jiang, J.M. Effects of (-)-gallocatechin-3-gallate on tetrodotoxin-resistant voltage-gated sodium channels in rat dorsal root ganglion neurons. Int. J. Mol. Sci. 2013, 14, 9779-9789. [CrossRef] [PubMed]

33. Abdelsayed, M.; Ruprai, M.; Ruben, P.C. The efficacy of Ranolazine on E1784K is altered by temperature and calcium. Sci. Rep. 2018, 8, 3643. [CrossRef] [PubMed]

34. El-Battrawy, I.; Lang, S.; Zhao, Z.; Akin, I.; Yucel, G.; Meister, S.; Patocskai, B.; Behnes, M.; Rudic, B.; Tulumen, E.; et al. Hyperthermia Influences the Effects of Sodium Channel Blocking Drugs in Human-Induced Pluripotent Stem Cell-Derived Cardiomyocytes. PLoS ONE 2016, 11, e0166143. [CrossRef] [PubMed]

35. Deng, H.M.; Yin, S.T.; Yan, D.; Tang, M.L.; Li, C.C.; Chen, J.T.; Wang, M.; Ruan, D.Y. Effects of EGCG on voltage-gated sodium channels in primary cultures of rat hippocampal CA1 neurons. Toxicology 2008, 252, 1-8. [CrossRef]

36. Kim, T.H.; Lim, J.M.; Kim, S.S.; Kim, J.; Park, M.; Song, J.H. Effects of (-) epigallocatechin-3-gallate on Na(+) currents in rat dorsal root ganglion neurons. Eur. J. Pharmacol. 2009, 604, 20-26. [CrossRef]

37. Salazar, P.B.; de Athayde Moncorvo Collado, A.; Canal-Martinez, V.; Minahk, C.J. Differential inhibition of human erythrocyte acetylcholinesterase by polyphenols epigallocatechin-3-gallate and resveratrol. Relevance of the membrane-bound form. BioFactors 2017, 43, 73-81. [CrossRef]

38. Ingolfsson, H.I.; Koeppe, R.E., 2nd; Andersen, O.S. Effects of green tea catechins on gramicidin channel function and inferred changes in bilayer properties. Febs Lett. 2011, 585, 3101-3105. [CrossRef]

39. Gamal El-Din, T.M.; Lenaeus, M.J.; Zheng, N.; Catterall, W.A. Fenestrations control resting-state block of a voltage-gated sodium channel. Proc. Natl. Acad. Sci. USA 2018, 115, 13111-13116. [CrossRef]

40. Henning, S.M.; Niu, Y.; Lee, N.H.; Thames, G.D.; Minutti, R.R.; Wang, H.; Go, V.L.; Heber, D. Bioavailability and antioxidant activity of tea flavanols after consumption of green tea, black tea, or a green tea extract supplement. Am. J. Clin. Nutr. 2004, 80, 1558-1564. [CrossRef]

41. Chow, H.H.; Cai, Y.; Hakim, I.A.; Crowell, J.A.; Shahi, F.; Brooks, C.A.; Dorr, R.T.; Hara, Y.; Alberts, D.S. Pharmacokinetics and safety of green tea polyphenols after multiple-dose administration of epigallocatechin gallate and polyphenon E in healthy individuals. Clin. Cancer Res. 2003, 9, 3312-3319. [PubMed]

42. Ullmann, U.; Haller, J.; Decourt, J.P.; Girault, N.; Girault, J.; Richard-Caudron, A.S.; Pineau, B.; Weber, P. A single ascending dose study of epigallocatechin gallate in healthy volunteers. J. Int. Med Res. 2003, 31, 88-101. [CrossRef] [PubMed]

43. Lee, M.J.; Maliakal, P.; Chen, L.; Meng, X.; Bondoc, F.Y.; Prabhu, S.; Lambert, G.; Mohr, S.; Yang, C.S. Pharmacokinetics of tea catechins after ingestion of green tea and (-)-epigallocatechin-3-gallate by humans: Formation of different metabolites and individual variability. Cancer Epidemiol. Biomark. Prev. 2002, 11, 1025-1032.

44. Narumi, K.; Sonoda, J.; Shiotani, K.; Shigeru, M.; Shibata, M.; Kawachi, A.; Tomishige, E.; Sato, K.; Motoya, T. Simultaneous detection of green tea catechins and gallic acid in human serum after ingestion of green tea tablets using ion-pair high-performance liquid chromatography with electrochemical detection. J. Chromatography. Banalytical Technol. Biomed. Life Sci. 2014, 945-946, 147-153. [CrossRef] [PubMed]

45. Lambert, J.D.; Lee, M.J.; Lu, H.; Meng, X.; Hong, J.J.; Seril, D.N.; Sturgill, M.G.; Yang, C.S. Epigallocatechin-3-gallate is absorbed but extensively glucuronidated following oral administration to mice. J. Nutr. 2003, 133, 4172-4177. [CrossRef] [PubMed]

46. Yang, C.S.; Wang, X.; Lu, G.; Picinich, S.C. Cancer prevention by tea: Animal studies, molecular mechanisms and human relevance. Nat. Reviews. Cancer 2009, 9, 429-439. [CrossRef] 
47. Lambert, J.D.; Lee, M.J.; Diamond, L.; Ju, J.; Hong, J.; Bose, M.; Newmark, H.L.; Yang, C.S. Dose-dependent levels of epigallocatechin-3-gallate in human colon cancer cells and mouse plasma and tissues. Drug Metab. Dispos. Biol. Fate Chem. 2006, 34, 8-11. [CrossRef]

48. Nagle, D.G.; Ferreira, D.; Zhou, Y.D. Epigallocatechin-3-gallate (EGCG): Chemical and biomedical perspectives. Phytochemistry 2006, 67, 1849-1855. [CrossRef]

49. Krupkova, O.; Ferguson, S.J.; Wuertz-Kozak, K. Stability of (-)-epigallocatechin gallate and its activity in liquid formulations and delivery systems. J. Nutr. Biochem. 2016, 37, 1-12. [CrossRef]

50. Li, N.; Taylor, L.S.; Ferruzzi, M.G.; Mauer, L.J. Kinetic study of catechin stability: Effects of pH, concentration, and temperature. J. Agric. Food Chem. 2012, 60, 12531-12539. [CrossRef]

51. Jo, S.; Kim, T.; Iyer, V.G.; Im, W. CHARMM-GUI: A web-based graphical user interface for CHARMM. J. Comput. Chem. 2008, 29, 1859-1865. [CrossRef] [PubMed]

52. Lee, J.; Cheng, X.; Swails, J.M.; Yeom, M.S.; Eastman, P.K.; Lemkul, J.A.; Wei, S.; Buckner, J.; Jeong, J.C.; Qi, Y.; et al. CHARMM-GUI Input Generator for NAMD, GROMACS, AMBER, OpenMM, and CHARMM/OpenMM Simulations Using the CHARMM36 Additive Force Field. J. Chem. Theory Comput. 2016, 12, 405-413. [CrossRef] [PubMed]

53. Wu, E.L.; Cheng, X.; Jo, S.; Rui, H.; Song, K.C.; Davila-Contreras, E.M.; Qi, Y.; Lee, J.; Monje-Galvan, V.; Venable, R.M.; et al. CHARMM-GUI Membrane Builder toward realistic biological membrane simulations. J. Comput. Chem. 2014, 35, 1997-2004. [CrossRef] [PubMed]

54. Klauda, J.B.; Venable, R.M.; Freites, J.A.; O'Connor, J.W.; Tobias, D.J.; Mondragon-Ramirez, C.; Vorobyov, I.; MacKerell, A.D., Jr.; Pastor, R.W. Update of the CHARMM all-atom additive force field for lipids: Validation on six lipid types. J. Phys. Chemistry. B 2010, 114, 7830-7843. [CrossRef] [PubMed]

55. Jorgensen, W.L.; Chandrasekhar, J.; Madura, J.D.; Impey, R.W.; Klein, M.L. Comparison of simple potential functions for simulating liquid water. J. Chem. Phys. 1983, 79, 926-935. [CrossRef]

56. Parrinello, M.; Rahman, A. Polymorphic transitions in single crystals: A new molecular dynamics method. J. Appl. Phys. 1981, 52, 7182-7190. [CrossRef]

57. Nosé, S. A unified formulation of the constant temperature molecular dynamics methods. J. Chem. Phys. 1984, 81, 511-519. [CrossRef]

58. Darden, T.; York, D.; Pedersen, L. Particle mesh Ewald: An N·log(N) method for Ewald sums in large systems. J. Chem. Phys. 1993, 98, 10089-10092. [CrossRef]

59. Abraham, M.J.; Murtola, T.; Schulz, R.; Páll, S.; Smith, J.C.; Hess, B.; Lindahl, E. GROMACS: High performance molecular simulations through multi-level parallelism from laptops to supercomputers. SoftwareX 2015, 1-2, 19-25. [CrossRef]

60. Zoete, V.; Cuendet, M.A.; Grosdidier, A.; Michielin, O. SwissParam: A fast force field generation tool for small organic molecules. J. Comput. Chem. 2011, 32, 2359-2368. [CrossRef]

Sample Availability: Samples of Epigallocatechin-3-Gallate are available from the authors.

(C) 2020 by the authors. Licensee MDPI, Basel, Switzerland. This article is an open access article distributed under the terms and conditions of the Creative Commons Attribution (CC BY) license (http://creativecommons.org/licenses/by/4.0/). 